\title{
SUB-REGISTRO DE NASCIMENTO EM SALVADOR, BA (BRASIL)*
}

Maura Maria Guimarães de Almeida **

\begin{tabular}{l|l|}
\cline { 2 - 2 } & RSPUB9/465 \\
\hline
\end{tabular}

ALmEIDA, M. M. G. de Sub-registro de nascimento em Salvador, BA (Brasil)

Rev. Saúde públ., S. Paulo, $13: 208-19,1979$.

Resumo: Visando quantificar o sub-registro de nascimento e identificar fatores que podem condicionar a deficiência do registro de nascimento entre crianças menores de um ano, foram feitas 2.893 entrevistas em uma amostra probabilistica de domicilios, da área urbana do municipio de Salvador, BA (Brasil), em 1977. Na população do estudo, 32,0\% das crianças não foram registradas. Para crianças vivas, com mais de 15 dias, o sub-registro de nascimento foi de 29,9\%, e para crianfas, com mais de 60 dias (prazo legal para registro), o sub-registro foi de $27,5 \%$. As variáveis intervenientes, positivamente associadas ao registro de nascimento em Salvador, são: nivel de renda da mãe, escolaridade dos pais, situação conjugal, filiação dos pais a instituições de seguro social, classificaçẫo do bairro de residência e batismo. A probabilidade do registro diminui com o aumento do número de filhos. Entre as crianças com registro de nascimento, $41,4 \%$ foram registradas depois de 15 dias e $14,0 \%$ após 60 dias do nascimento.

UNITERmos: Registro de nascimento, Salvador, BA, Brasil.

O sub-registro de nascimento é um problema que existe com maior ou menor frequêencia em todo o Brasil e na América Latina. Quanto maior o sub-registro, menos reais são os indicàdores que utilizam - número de nascidos vivos como base de referência, como por exemplo: Coeficiente de Mortalidade Infantil, Coeficiente de Mortalidade Neonatal, Coeficiente de Mortalidade Perinatal, Coeficiente de Natimortalidade, Coeficiente de Mortalidade Materna, Coeficiente de Natalidade Geral e Coeficiente de Fertilidade Geral.
A necessidade de dados estatísticos corretos e confiáveis é reconhecida pelos planejadores de saúde como indispensável ao trabalho de Saúde Pública. São eles elementos básicos no planejamento dos programas de saúde.

\subsection{Registro de Nascimento}

"No Brasil, até o tempo do Império, não se conhecia outro registro que não o religioso. O Decreto 9.886 , de 07 de março de 1888 , foi o primeiro ato a régulamentar,

* Resumo da Dissertação apresentada ao Mestrado de Saúde Comunitária da Universidade Federal da Bahia - 1978. Patrocinado pela Ford Foundation.

* Po Departamentọ de Enfermagem Comunitária da Escola de Enfermagem da. Universidade Federal da Bahia - Campus Universitário - Canela - 40000 - Salvador, BA - Brasil. 
ALMEIDA, M. M. G. de Sub-registro de nascimento em Salvador, BA (Brasil). Rev. Saude públ., S. Paulo, $13: 208-19,1979$.

entre nós, o registro de nascimento, casamento e óbito, que ocorressem no Império. Com a República, foi determinada a manutenção e obrigatoriedade dos registros públicos"12.

A lei de registros públicos número 6.015, de 31 de dezembro de 1973, determina sobre o registro de nascimento, nos Artigos 46,50 e 52 ,

Estudos para quantificar o sub-registro de nascimento foram realizados por Scorzelli ${ }^{14}$ (1947), Saade ${ }^{9}$ (1947), Moraes ${ }^{\top}$ (1949), Milanesi e Silva ${ }^{6}$ (1968), Silva ${ }^{11}$ (1970) entre crianças vivas. Suarez ${ }^{15}$ (1968), Laurenti e col.4 (1971) estudaram o sub-registro entre crianças falecidas. Alguns autores estudaram quais os fatores que condicionam o sub-registro de nascimento, entre eles encontramos Moraes ${ }^{7}$, Rosado ${ }^{8}$, Suarez ${ }^{15}$, Levy e col.5 e Silveira e Soboll 1is.

$\mathrm{Na}$ Bahia não existem trabalhos sobre sub-registro de nascimento, condicionando o desconhecimento de um percentual de correção que possibilite cálculos mais reais para os indicadores que utilizam o número de nascidos vivos como base de referência.

\subsection{Objetivos}

- Quantificar o sub-registro de nascimento na zona urbana de Salvador.

- Identificar fatores que podem condicionar a deficiência do registro de nascimento na zona urbana de Salvador.

- Estabelecer um percentual de correção para o cálculo dos coeficientes que utilizam o número de nascidos vivos em Salvador.

\section{MATERIAL E MÉTODOS}

Técnica de amostragem - $\mathrm{O}$ plano de amostragem foi realizado por uma equipe do $\mathrm{BNH} / \mathrm{SETRABES}$ 2, visando ser representativa para a pesquisa "Diagnóstico Habitacional em Salvador", sendo utilizado com algumas modificações devido aos limitados recursos e aos objetivos propostos nesta pesquisa.

Das 7 zonas do municipio de Salvador, foram consideradas "área da pesquisa" 6 zonas (ns. 1 a 5 e 7) localizadas na área urbana; portanto não constou a zona 6 , que abrange os bairros da zona suburbana. (Tabela 1).

Foi utilizada uma amostra probabilistica de domicilios, sendo a criança, nascida no último ano na data da entrevista, a unidade sobre a qual levantou-se informações através um questionário específico.

Técnica e instrumentos de coleta de dados - A técnica utilizada foi a entrevista estruturada, usando-se, como instrumento, um questionário pré-testado. A coleta, realizada por entrevistadores treinados, estudantes universitários, sob contínua supervisão, era feita através de sorteio de alguns domicilios, que eram outra vez visitados com o fim de conferir as informaçóes. A pessoa entrevistada, para o preenchimento do questionário, foi de preferência a mãe ou o pai da criança nascida a menos de um ano do dia da entrevista.

Foram visitados 3.020 domicílios e reallzadas 2.893 entrevistas, correspondendo a $1,14 \%$ dos domicílios estimados para a área da pesquisa.

Foram encontradas 477 crianças nascidas em Salvador no último ano; entre estas, três não tiveram o questionário preenchido por recusa da mãe. Das 474 crianças, que constituiu a população de estudo, dez foram gemelares, portanto, cinco partos foram gemelares.

\section{RESULTADOS E DISCUSSÃO}

Foram encontradas $151(31,9 \%)$ crianças sem registro de nascimento, $321(67,7 \%)$ registradas, e duas que as māes ignoravam se haviam sido registradas, por terem sido adotadas logo após o nascimento. $\mathrm{O}$ per- 


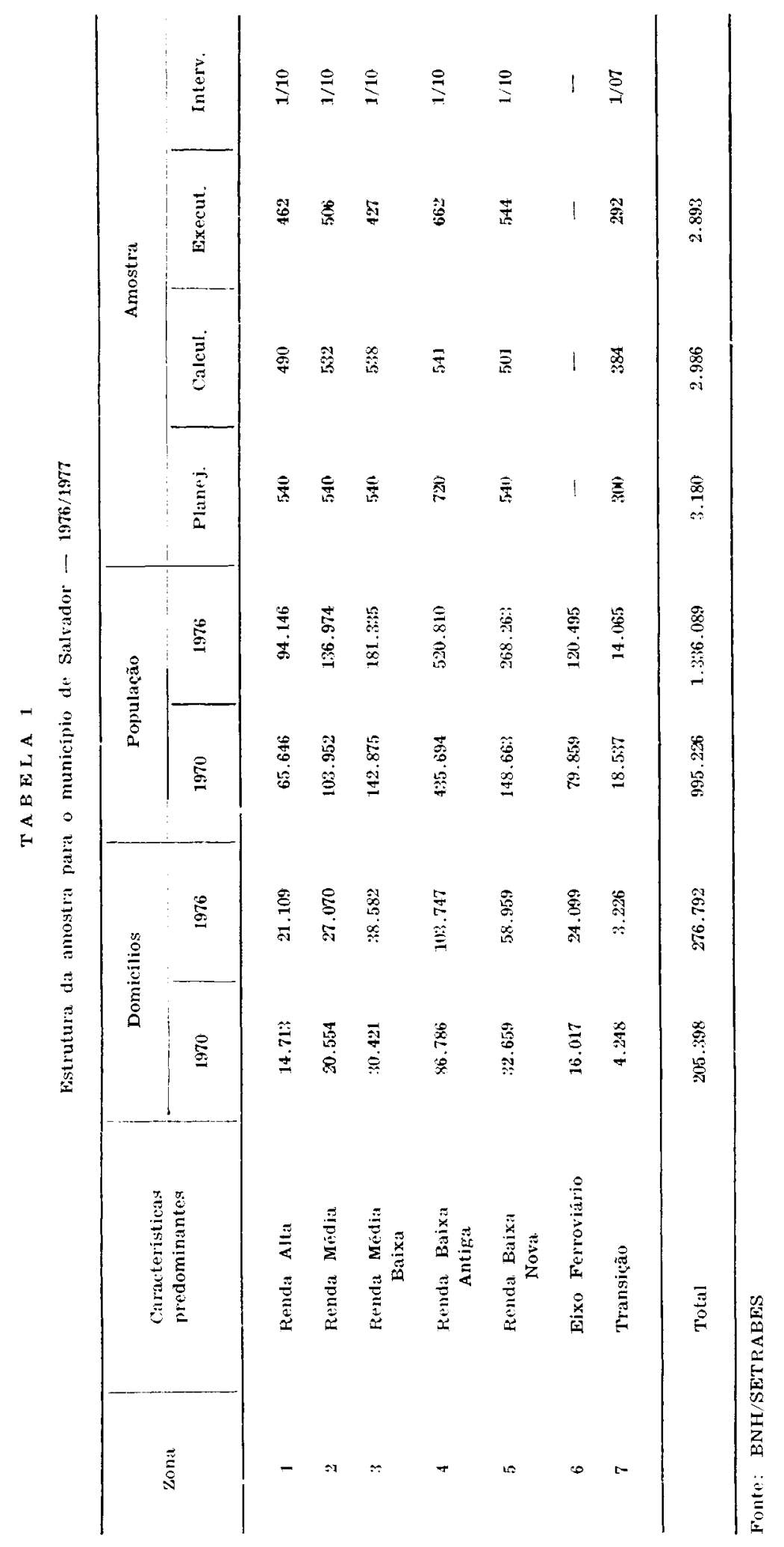


ALMEIDA, M. M. G. de Sub-registro de nascimento em Salvador. BA (Brasil). Rev, Saúde públ., S. Paulo, 13:208-19, 1979.

centual de crianças sem registro foi semelhante ao encontrado para Vitória do Espirito Santo, em $1946^{\circ}$.

Considerando a idade da criança, verificou-se entre as crianças vivas, com mais de 15 dias, um sub-registro de $29,9 \%$, e para as crianças, com mais de 60 dias, de $27,5 \%$, bem mais alto do que o encontrado por Milanesi e Silva ' (1968), para São Paulo. Acredita-se que o sub-registro de nascimento em São Paulo seja menor do que o de Salvador (BA), devido a região sul ser mais desenvolvida, com características sócio-econômico-culturais diferentes de Salvador.

Apesar de aparecerem muitas crianças seml registro de nascimento, todas as pessoas entrevistadas informaram conlecer a exigência legal deste registro. Algumas mães informaram, durante a entrevista, que outros filhos não haviam sido registrados.

Vários foram os motivos apresentados como justificativa para a criança não ter sido registrada, aparecendo com percentuais maiores a falta de tempo $(29,8 \%)$, falta de dinheiro $(28,5 \%)$ e a displicência do pai $(24,5 \%)$; são, ainda, referidas a situação conjugal, a dúvida na escolha do nome, a falta de documentos dos pais, a distância do cartório, a falha nas informações e a morte da criança.

Dentre as 321 crianças registradas, 304 $(94,7 \%)$ tiveram o registro feito pelo pai, enquanto apenas $16(5,0 \%)$ foram registradas pela mãe, e uma criança foi registrada por alguém sem nenhum grau de parentesco, que a adotou. As crianças poderiam ser registradas pelas mães, constando ou não (impedimento do pai) no documento, a paternidade. Isso não ocorreu talvez por ignorância de que outra pessoa poderia fazer o registro, ou por interferência cultural, que só aceita o registro pelo pai.
Essa suposição coincide conn as principais causas do sub-registro referidas pelas entrevistadas, "a displicência e falta de tempo do pai"..., de fato referem-se à necessidade da legitimação do filho vir através do pai. Convém, entretanto, chamar atenção para que muitas das crianças não registradas provêm de situações conjugais onde a presença do pai inexiste.

É importante considerar a função social do registro pois, sem o objetivo da legitimidade e do salário familia, a criança não é registrada; além disso, a lei só admite o registro de filhos fora do matrimônio, depois de desfeito o vinculo matrimonial. ${ }^{1}$

O registro de nascimento foi feito, uniformemente, em todos os meses do ano, embora essa uniformidade não fosse acompanhada pelos nascimentos.

\subsection{Renda}

Nesta pesquisa, a renda foi estudada através das zonas, classificação do bairro de residência, nivel de renda do pai e nivel de renda da mãe.

Crianças sem registro de nascimento apareceram em todas as zonas de Salvador, sem haver uma diferença estatisticamente significante, apesar do percentual variar de $24,0 \%$ na zona 1 , de renda mais alta, para $39,3 \%$ na zona 7 , de renda mais baixa. (Tabela $\left.2 \mathrm{x}_{5}{ }_{5}=6,891 ; \mathrm{p}>0,05\right)$.

0 registro de nascimento, associado à renda, foi referido por Moraes ?, 1949 (profissão do pai e condição econômica), Rosado ${ }^{8}, 1949$ (profissão e salário), Suarez ${ }^{15}, 1968$ (dificuldade econômica para pagar o registro) e Levy 5, 1971 (classe social). 
ALMEIDA. M. M. G. de Sub-registro de nascimento em Salvador. BA (Brasil), Rev. Saúde públ., S. Paulo. 13:208-19. 1979.

\section{TA B E L A 2}

Crianças nienores de um ano. nascidas em Salvador, segundo a zona de residência e o registro de nascimento - maio a setembro - 1977.

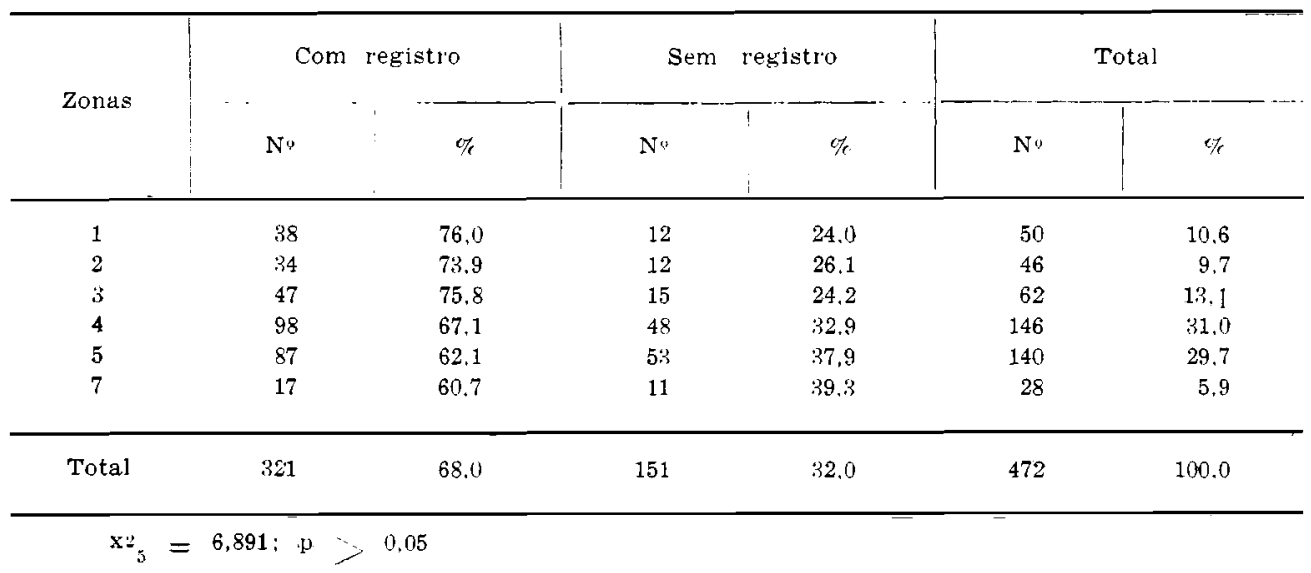

Experiências em pesquisas anteriores demonstraram ser difícil conseguir que o entrevistado quantificasse a renda familiar, principalmente aquelas mulheres que desconhecem a renda do companheiro, e quando estes não recebem um ordenado fixo, as dificuldades aumentam.

Visando reduzir esse problema, utilizouse os critérios já citados para estudar a influência da renda no registro de nasci- mento. Convém, entretanto, chamar atençâo para o fato de que os critérios escolhidos apresentam alguns inconvenientes.

Porèm, classificando os bairros, onde residiam as crianças, em 3 estratos ${ }^{3}$, classe $\mathrm{A}=$ alta, $\mathrm{B}=$ média e $\mathrm{C}=$ baixa, encontrou-se associação entre a classificação do hairro e o registro de nascimento. (Tabela $\left.3 x_{2}=6,236 ; p<0,05\right)$.

T A B E L A :

Crianças menores de 1 ano. nascidas em Salvador, segundo a classificação do bairro e o registro de nascimento - maio a setembro - 1977.

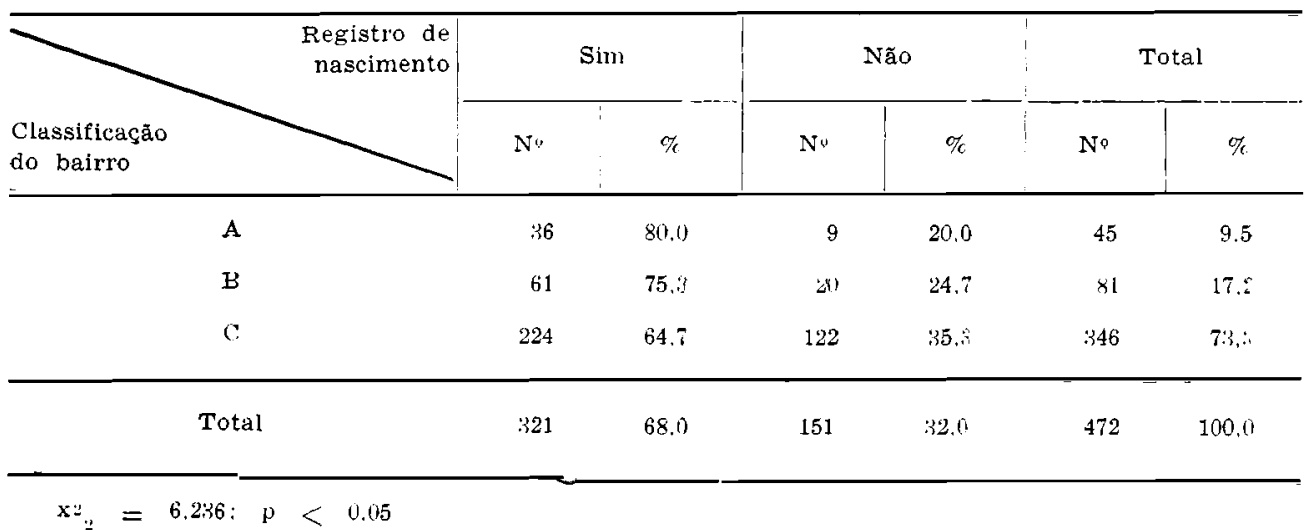


ALMEIDA, M. M. G. de Sub-registro de nascimento em Salvador, BA (Brasil), Rev. Saúl. públ., S. Paulo, 13:208-19, 1979.

Nos critérios de estratificação por zona e por classificação do bairro de residência, destaca-se o fato de Salvador ser uma cidade em que se encontram domicilios de classe A (mais elevada), tendo como vizinhos domicílios paupérrimos, agrupados em favelas (classe C). Por outro lado, as empregadas domésticas, que dormiam no emprego, integravam o grupo domiciliar e foram incluidas nas zonas de renda mais alta. É possivel que essas situaçōes tenham influido para que as diferenças existentes entre as zonas, quanto ao registro de nascimento, não fossem estatisticamente significantes ao nivel de $5 \%$.

Entre as crianças residentes nos bairros classe A, 20,0\% não tinham registro de nascimento, entre as residentes nos bairros classe $B, 24,7 \%$ e entre as residentes nos bairros classe $\mathrm{C}, 35,3 \%$; percentuais mais bajxos do que os referidos por Levy ${ }^{5}$ (1971), que encontrou, também, associação entre registro de nascimento e a classe social, em um estudo feito em maternidades de São Paulo.

É interessante notar que o nivel de renda foi estabelecido de acordo com a ocupação, mas a pesquisa não identificou aqueles que estavam desempregados, embora esse fato seja minimizado sabendo-se que a maioria das crianças $(86,7 \%)$ tem pais que pertencem a instituições de seguro social.

Não foi encontrada diferença estatisticamente significante entre o nível de renda do pai e o registro de nascimento, embora se observe o maior percentual de crianças sem registro para o nivel 1 de mais baixa renda, $(55,6 \%)$ e o menor de $13,5 \%$ para o nivel 7 de renda mais alta. (Tabela 4 $\left.x_{i}{ }^{2}=13,663 ; p>0,05\right)$.

Os dados demonstraram, a um nivel de significância de $5 \%$, associação entre 0 nivel de renda da mãe e o registro de nascimento. (Tabela $5 \mathrm{x}_{6}{ }^{2}=21,167 ; \mathrm{p}<$ $0,05)$.

Outro fator que pode ter influenciado na relação entre o registro de nascimento e o nivel de renda do pai foi que $43,0 \%$ das mães não tinham uma situação de casamento legal, vivendo, muitas vezes, afastadas do pai da criança; portanto, a renda desse pai, distante ou impedido de assumir uma situação legal, provavelmente, năo influiu no registro de nascimento.

Moraes ${ }^{7}$ e Rosado 8 encontraram associação entre o registro de nascimento e a profissão do pai, porém fizeram uma classificação muito geral. Além disso, os dados de Rosado\%, referem-se às famílias que apresentavam todas as pessoas registradas ou não registradas.

O nivel de renda da mãe parece influenciar mais diretamente a situação do registro da criança, apesar de $65,1 \%$ das mães desenvolverem atividades sem remuneração, sendo mantidas pelo companheiro ou familiares.

A mãe, como já foi referido anteriormente, não é responsável diretamente pelo ato de registrar, mas suas características sócio-econômico-culturais provavelmente interferem para que a criança seja registrada.

\subsection{Escolaridade}

A escolaridade dos pais é um dos fatores que condicionam o registro de nascimento. Observou-se uma diferença estatisticamente significante entre a média de escolaridade do pai que fez o registro $(\bar{x}=8,4) \mathrm{e}$ daquele que não o fez $(\bar{x}=6,1)$. (Tabela 6 $\left.t_{402}=4,01 ; p<0,05\right)$.

A média de escolaridade da mãe foi mais baixa do que a do pai, em ambos os grupos. As mães de crianças registradas tiveram uma média de escolaridade $\left(\bar{X}_{1}=7,8\right)$ significantemente mais alta do que as mães das crianças sem registro $\left(\bar{x}_{t 2}=5,6\right) . \quad\left(\right.$ Tabela $7 \quad t_{463}=5,13 ;$ $\mathrm{p}<0,05)$.

$O$ achado de que o registro de nascimento aumenta a medida que a instrução dos pais se eleva coincide com os de Moraes ${ }^{7}$ e Rosado ${ }^{8}$. 
ALmeidA, M. M. G. de Sub-registro de nascimento em Salvador, BA (Brasil), Rev, Saúde públ., S. Paulo, 13:208-19, 1979.

TABELA 4

Crianças menores de 1 ano. nascidas em Salvador. segundo o nível de renda do pai e " registro de nascimento - maio a setembro - 1977.

\begin{tabular}{|c|c|c|c|c|c|c|}
\hline \multirow[b]{2}{*}{$\begin{array}{l}\text { Nivel de } \\
\text { renda do pai }\end{array}$} & \multicolumn{2}{|c|}{$\sin$} & \multicolumn{2}{|c|}{ Năo } & \multicolumn{2}{|c|}{ Total } \\
\hline & $\mathrm{N}^{\circ}$ & $\%$ & $N^{9}$ & $\%$ & $\mathrm{~N}^{\circ}$ & $\%$ \\
\hline \multirow{9}{*}{. } & 6 & 66.7 & 3 & 33.3 & 9 & 1,9 \\
\hline & 8 & 44.4 & 10 & 55.6 & 18 & 3.8 \\
\hline & $5:$ & 63.9 & ;0 & $: 36.1$ & $x: 1$ & 17.6 \\
\hline & $10: 3$ & 67.8 & 49 & 32,2 & 152 & $: 32.2$ \\
\hline & 78 & 69.6 & $: 34$ & 30.4 & 112 & 23.7 \\
\hline & 11 & 78.6 & 3 & 21.4 & 14 & 3.19 \\
\hline & 26 & 78.8 & 7 & 21.2 & 33 & 7.0 \\
\hline & 32 & 86,5 & 5 & 13.5 & 37 & 7,8 \\
\hline & 4 & 28,6 & 10 & 71.4 & 14 & 3.0 \\
\hline Total & 321 & 68,0 & 151 & 32,0 & 472 & 100.0 \\
\hline
\end{tabular}

$x_{i}^{2}=13.663: p>0,05$

T A BELA S

Crianças menores de 1 ano. nascidas em Salvador, segundo o nivel de renda da mãe e o registro de nascimento - maio a setembro - 1977.

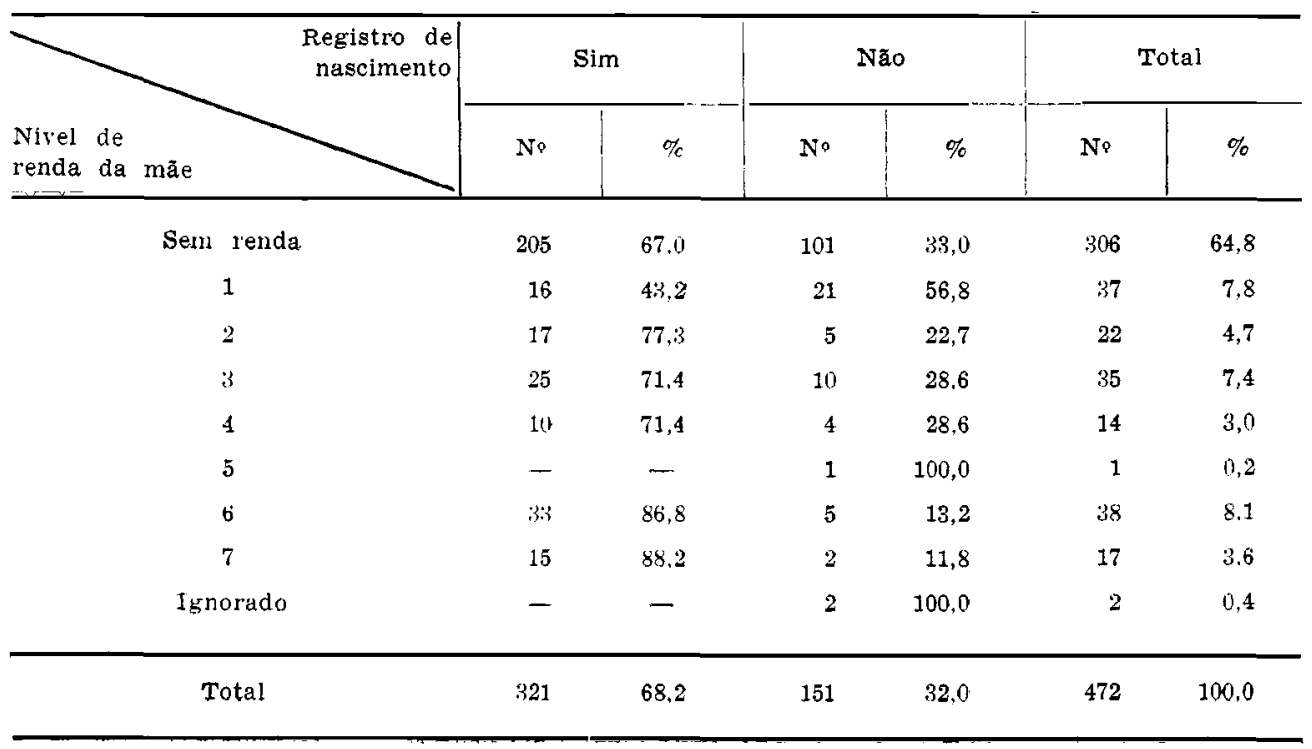

$x_{0}{ }^{2}=21,167 ; p<0,05$ 
ALMEIDA, M. M. G. de Sub-registro de nascimento em Salvador, BA (Brasil). Rev. Saúde públ., S. Paulo, 13:208-19, 1979.

T A B E L A 6

Crianças menores de 1 ano, nascidas em Salvador. segundo a escolaridade do pai e o registro de nascimento - maio a setembro - 1977.

\begin{tabular}{l}
$\begin{array}{r}\text { Registro de } \\
\text { nascimento }\end{array}$ \\
\hline $\begin{array}{l}\text { Escalaridade } \\
\text { do pai }\end{array}$
\end{tabular}

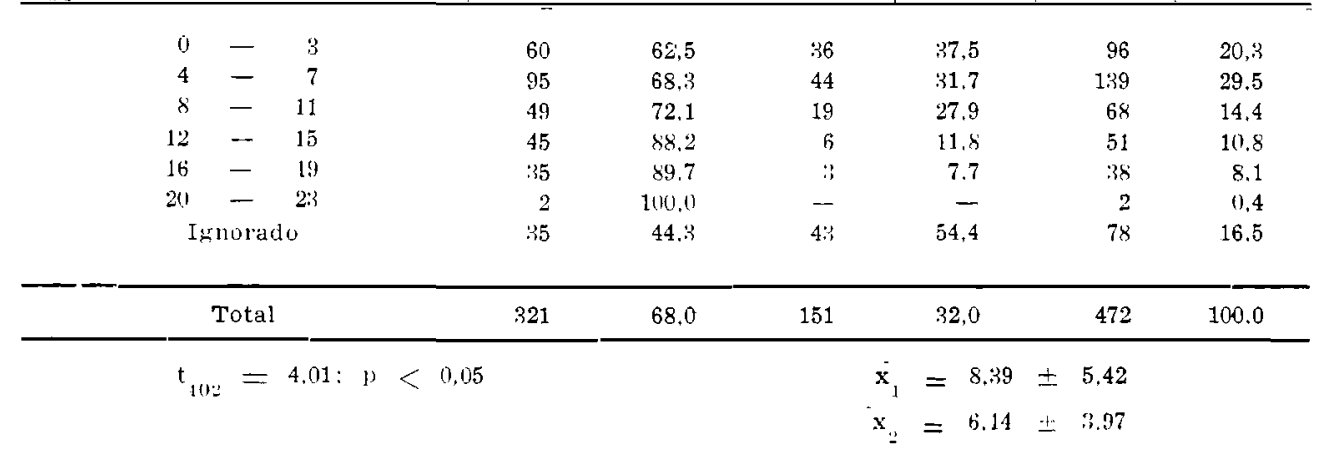

\subsection{Numero de filhos}

O registro de nascimento foi associado à ordens de nascimento, exceto na $5 "$, 6", $33,431 ; n<0,05)$. Nota-se, em todas as ordens de nascimento, exceto na 5a, 6a., e 9* ordens, que o número de crianças registradas foi maior do que o das não registradas.
Percebe-se que os primeiros filhos são registrados com maior regularidade. Isto ficou evidente quando se verificou uma média de 2,7 fillhos vivos para as mães de crianças registradas, significantemente menor do que a média de 3,4 filhos para as mães de crianças sem registro.

TABELA 7

Crianças menores de 1 ano. nascidas em Salvador, segundo a escolaridade da mãe e o registro de nascimento - maio a setembro - 1977.

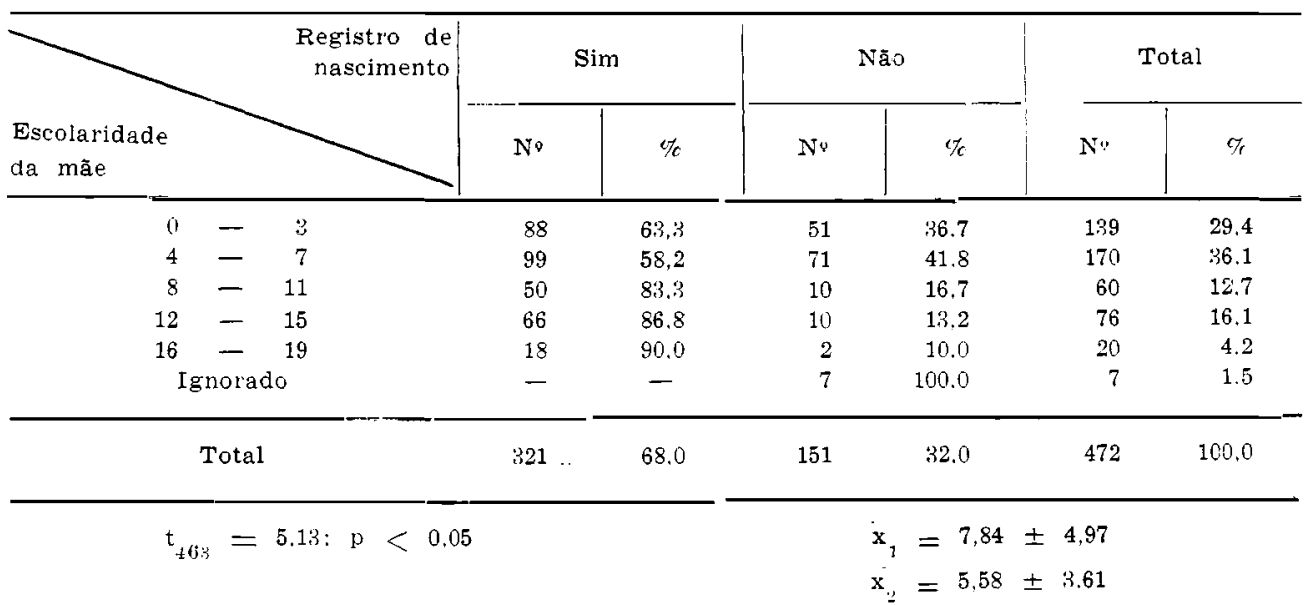


ALMEIDA. M. M. G. de Sub-registro de nascimento em Salvador, BA (Brasil). Rev, Saúde públ., S. Paulo, 13:208-19, 1979.

\subsection{Situação conjugal}

Verificou-se associação entre o registro de nascimento e a situação conjugal da mãe. (Tabela $9 \mathrm{x}_{22}{ }^{2}=66,459 ; \mathrm{p}<0,05$ ). Nota-se que as mães, com uma família estabelecida, mesmo sem um casamento legal, apresentaram um percentual de crian- ças sem registro menor do que as mães solteiras. Encontrou-se $56,8 \%$ de mães casadas, $30,9 \%$ amasiadas, $11,9 \%$ solteiras e $0,4 \%$ viúvas. Entre as casadas o percentual de crianças sem registro foi de $20,1 \%$, entre as amasiadas foi de $37,0 \%$, entre as viúvas $50,0 \%$, e entre as solteiras $75,0 \%$.

T A B E L A 8

Crianças menores de 1 ano, nascidas em Salvador, segundo a ordem de nascimento e registro - maio a setembro - 1977 .

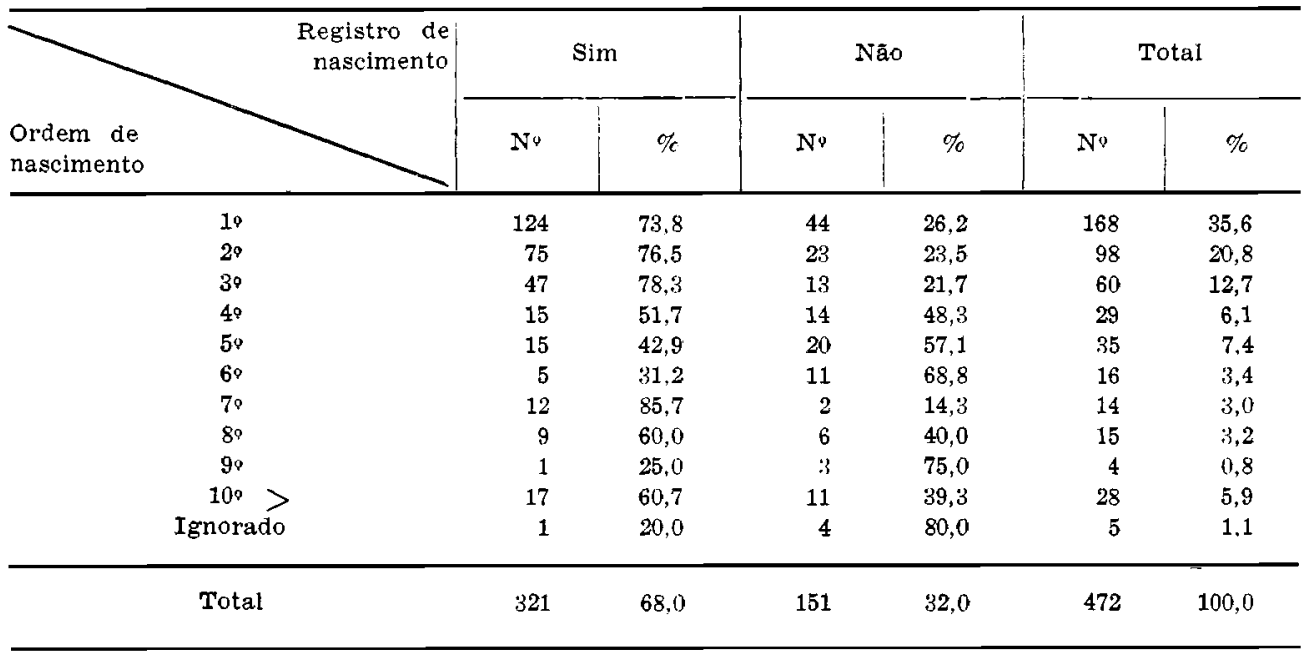

$\mathrm{x}_{6}{ }^{2}=33,431 ; \mathrm{p}<0,05$

T A B E L A 9

Crianças menores de 1 ano, nascidas em Salvador, segundo a situação conjugal da mãe e o registro de nascimento - maio a setembro - 1977.

\begin{tabular}{|c|c|c|c|c|c|c|}
\hline $\begin{array}{l}\text { Situaçâo conjugal } \\
\text { da mäe }\end{array}$ & \multicolumn{2}{|c|}{$\operatorname{Sin}$} & \multicolumn{2}{|c|}{ Não } & \multicolumn{2}{|c|}{ Total } \\
\hline Solteira & 14 & 25,0 & 42 & 50,0 & 56 & 11,0 \\
\hline Viúva & 1 & 50,0 & 1 & $\mathbf{5 0 , 0}$ & 2 & 0,4 \\
\hline Trotal & 321 & 68,0 & 151 & 32,0 & 472 & 100,0 \\
\hline
\end{tabular}

$$
\mathrm{x}_{2}^{2}=66,459 ; \mathrm{p}<0,05
$$


ALMEIDA, M. M. G. de Sub-registro de nascimento em Salvador, BA (Brasil). Rev. Saude públ., S. Paulo, 13:208-19, 1979.

Moraes ${ }^{7}$, estabeleceu a categoria de casados e de maritais (pais vivendo maritalmente), e Suarez ${ }^{15}$ analisou o registro de nascimento com as categorias de pais casados e não casados, não encontrando associação entre o registro e a situação conjugal. Acredita-se que o critério empregado nesta pesquisa identifica melhor a situação conjugal dos pais da criança.

\subsection{Local de nascimento}

Não foi encontrada associação entre o registro e o local de nascimento. Nasceram em hospitais $453(96,0 \%)$ das crianças, enquanto $19(4,0 \%)$ nasceram no domicílio.

\subsection{Sexo}

Os resultados demonstraram não haver associação entre o registro e o sexo da criança, o que parece afirmar não existir diferença quanto ao tipo de assistência que é dada aos filhos de sexos diferentes.

\subsection{Seguro social}

Entre as crianças estudadas, $86,9 \%$ têm pais que pertencem a instituiçōes de seguro social. Observou-se associação entre o régistro de nascimento e o seguro social. Benefícios proporcionados por essas instituições exigem a certidão de nascimento como documento comprovatório.

\subsection{Batismo}

Foi significante a diferença entre as crianças batizadas e não batizadas em relação ao registro de nascimento. Apenas $14,0 \%$ das crianças eram batizadas.

\subsection{Tempo de registro}

Embora 321 crianças tenham sido registradas, apenas $188(58,6 \%)$ obedeceram ao prazo de 15 dias, $88(27,4 \%)$ foram registradas entre 16 e 60 dias, e $45(14,0 \%)$ após os 60 dias. A mediana do tempo de registro foi de 14,4 dias, tendo variado de
0 a 333 dias. Entretanto, existe uma defasagem entre $o$ percentual de crianças registradas dentro do prazo legal $(58,6 \%)$ e o percentual de crianças registradas pelo pai $(94,7 \%)$. Logo, algumas crianças, embora registradas pelo pai, tiveram o registro feito fora do prazo legal.

Entre as crianças com registro de nascimento, $86,0 \%$ foram registradas até 60 dias; percentuais de $72,8 \%, 84,2 \%$ e $60,6 \%$ foram encontrados em Recife, Curitiba e Vitória, respectivamente, em 1946. Em Araraquara, $1949,97,4 \%$ das crianças foram registradas no prazo.7

Estudou-se o registro de nascimento sob todos os aspectos que se considerou importantes, para alcançar os objetivos propostos. Diante dos resultados encontrados (96,0\% dos partos foram feitos em maternidades), reforça-se a idéia de que o registro de nascimento seja feito na própria maternidade, onde a criança nasce, insistindo para que o registro seja realizado durante a permanência da mãe, na maternidade, diminuindo, assim, o sub-registro e o tempo de registro.

Deverá ser divulgada a lei de Registros Públicos 6.015 de 31.12 .1973 , que estabelece o registro de nascimento gratuito, para as crianças cujos pais não disponham da quantia estipulada para o registro.

Educar a população, principalmente através os meios de comunicação como rádio, televisão, jornais e cartazes é indispensável a um programa de incentivo ao registro de nascimento.

O percentual de sub-registro encontrado para o município de Salvador não reflete a situação dos outros municípios e da zona rural do Estado da Bahia. Sugere-se que outras pesquisas sejam feitas, para que se possa estabelecer o sub-registro de nascimento existente, não só para Salvador, mas para o Estado da Bahia e outros Estados do Brasil. 
ALmEIDA. M. M. G. de Sub-registro de nascimento em Salvador, BA (Brasil), Rev, Saude públ., S. Paulo, 13:208-19, 1979.

\section{CONCLUSÖES}

Os resultados encontrados permitiram-nos chegar as seguintes conclusões:

- Existe sub-registro de nascimento em Salvador. $\mathrm{Na}$ população em estudo $32,0 \%$ das crianças menores de um ano não eram registradas.

- Para crianças vivas, com mais de 15 dias, o sub-registro de nascimento foi de $29,9 \%$ e para crianças, com mais de 60 dias (prazo legal), o sub-registro foi de $27,5 \%$.

- As crianças que residem em bairros classe A (alta) são mais registradas do que as que residem em bairros classes $B$ (média) e $C$ (baixa).

- O tempo de registro variou de 0 a 333 dias, sendo a mediana de 14,4 dias.

Al.MEIDA, M. M. G. de [The under-registration of births in Salvador, BA (Brazil)/ Rev. Saúde públ., S. Paulo, 13:208-19, 1979.

ABSTRACT: In order to quantify the extent of the number of unregistered births and to identify the factors responsible for this, 2,893 interviews were carried out in a probabilistic sampling of homes in the urban area of Salvador, Bahia, in 1977. Thirty-two percent of the children under the age of 12 months identified in these interviews were still not registered. Excluding infants under 15 days of age, this percentage was $29.9 \%$, and among children over 60 days old (the maximum period permitted by law) it fell to $27.5 \%$. The intervening variables found to be positively associated with birth registration were maternal income, parental education, status of the residential area, coverage by social security, and baptism of the child. The probability of registration decreased at higher birth orders. Among the births registered, $41 \%$ were registered after the 15th day and $14 \%$ after the 60-day legal limit.

UNiterms: Birth certificates, Salvador, BA, Brazil.

\section{REFERENCIAS BIBLIOGRÁFICAS}

1. Batalha. W. de $\mathrm{S}$. C. Comentarios a Lei de Registros Públicos. Rio de Janeiro, Forense, 1977. v. 1.

2. DIAGNóstico habitacional em Salrador Salvador, BNH/SETRABES. 1976. [no prelo]

3. EMPRESA BAHIANA DE AGUAS E SANEAMENTO S/A (EMBASA). Plano Diretor do Abastecimento de Agua $e$ Conitrole de Poluiça da Grande Salrador: relatorio preliminar do balanso das necessidades e disponibilidades hidricas. São Paulo, 1973. r. 1. [mimeografado]
4. LAURENTI, $R$. et al. Sub-registro de nascimento de crianças falecidas com menos de um ano de idade. Rer. Satide puibl., S. Paulo, 5:237-42. 1971.

5. LEVY, M. S. et al. O registro de nascmento e sua importancia em planejamento materno-infantil. Rer. Sarde puibl., S. Paulo, 5:41-6, 1971.

6. MILANESI, M. L. \& SILVA, E. P. C Sub-registro de nascimento no Distrito de São Paulo. Rer. Saúle puibl., S. Paulo. 2:23-8, 1968.

7. Moraes, N. L. de A. Estudo sobre a importancia dos fatnres que podem 
ALMEIDA. M. M. G. de Sub-registro de nascimento em Salvador, BA (Brasil). Rev. Saúde públ., S. Paulo, 13:208-19. 1979.

condicionar a deficiência do registro de nascimentos. Rev. Serv. Saúde públ., Rio de Janeiro, 2:743-74, 1949.

8. ROSADO, P. Aspectos do registro civil de nascimentos em uma cidade do interior de Amazônia, 1938-1947. Rev. Serv. Saúde públ., Rio de Janeiro. 2:775-92. 1949.

9. SAADE, M. J. Verificação estatística do grau de deficiência do registro de nascimento, Rev. Serv. Saúde públ., Rio de Janeiro, 1:449-67. 1947.

10. SCORzELLI, A. R. Coleta de dados vitais em pequenas localidades. Rev. Serv. Saúde pribl., Rio de Janeiro. 1:397432. 1947.

11. SILVA, E. P. C. Estimativas de coeficientes $e$ indices vitais $e$ de sub-registros de nascimentos no distrito de $\mathrm{s}$. Paulo, baseadas em amostra probabilistica de domicilios. São Paulo, 1970. [Dissertação de Mestrado - Faculdade de Saúde Pública da USP].
12. SILVEIRA, M. H. \& LAURENTI, R. Os eventos vitais: aspectos de seus registros e inter-relação da legislação vigente com as estatísticas de saúle. Rev. Saúde públ., S. Paulo, 7:37-50. 1973.

13. SILVEIRA, M. H. \& SOBOLL, M.L. Subregistro de nascimento: aspectos educativos visando a sua diminuiçảo. Rev. Saúde públ., S. Paulo, 7:151-60, 1973.

14. SINGER, P. Demanda por alimentos na Região Metropolitana de Salvador. São Paulo, Centro Brasileiro de Análise e Planejamento, 1976. iCaderno CEBRAP, 23;

15. SUAREZ, L. Sub-registro de nascimento. São Paulo, 1968. [Dissertação de Mes. trado - Faculdade de Saúde Púhlica da USP]

Recebiao para publicação em 29/03/1974

Aprovado para publicaçāo em 19/06/19\%9 